\section{A comparison of two doses of epidural fentanyl}

To the Editor:

If no differences in operative pain were found when 25 or $50 \mu \mathrm{g}$ of fentanyl were used, was $25 \mu \mathrm{g}$ really necessary? In my experience, talking to patients reduces (often to zero) the need for extra medication when regional techniques are employed.

Robert W. Lamont MD

138 Cassandra Boulevard

Don Mills, Ontario M3A 1S9

\section{REFERENCE}

1 Yee I, Carstoniu J, Halpern S, Pittini R. A comparison of two doses of epidural fentanyl during Caesarean section.

Can J Anaesth 1993; 40: 722-5..

\section{REPLY}

Thank you for giving me an opportunity to reply to $\mathrm{Dr}$. Lamont's letter.

In our study, we used the incidence of supplemental analgesia use as one measure of effectiveness of regional anaesthesia. We used this measure because it is clinically relevant and because it has been used previously.

Whether or not a placebo (narcotic) group should have been included in the study is debatable. Since all anaesthetists in our institution at the time the study was performed used supplemental epidural fentanyl we chose not to include a placebo.

Dr. Lamont makes the very good point that communication with the patient often reduces or eliminates the need for supplemental intravenous analgesia during Caesarean section. I wholeheartedly agree that if a non-pharmacological intervention is available and effective, it should be used in preference to drug therapy. However, our study did not address that issue.

S. Halpern MD FRCPC

Department of Anaesthesia

Women's College Hospital

Toronto, Ont.

\section{Packaging of saline and Quelicin (Abbott)}

To the Editor:

I am writing to voice concern with the similar packaging of normal saline $10 \mathrm{ml}$ (DIN 00037796, Abbott 4888(13) and Quelicin $20 \mathrm{ml}$ (succinylcholine, DIN $00038172 \mathrm{Ab}-$ bott 6629). We find the similarity in packaging of these vials, both in the colour of the tops (yellow) and the colour of the labels, both white and yellow background with red printing, unacceptable and potentially dangerous to patient care, particularly in an emergency situation where speed of identification of a drug is of utmost importance.

Steven Dain MD FRCPC

Saint Joseph's Health Centre

London, Ont.

\section{REPLY}

In response to $D r$. Steven Dain's concern about the packaging similarities of Abbott's $0.9 \%$ sodium chloride $10 \mathrm{ml}$ vial and Quelicin $20 \mathrm{ml}$ vial, there are differences between each container. The front panel of the sodium chloride vial has a large "I DOSE" printed on the front of the glass vial. Quelicin is packaged in a plastic multiuse vial. Although both vials have yellow capped tops, all medications administered to patients must be identified by inspecting the product labelling. We appreciate customer comments and to this end, Abbott will be packaging the $20 \mathrm{ml}$ Quelicin vial with a white cap.

Jim Currie

Abbott Laboratories, Limited

Montreal (Quebec)

\section{Prolonged use of isoflurane in asthma}

To the Editor:

Volatile anaesthetic agents are of value in the management of patients with severe bronchospasm requiring mechanical ventilation. ${ }^{1,2}$ Since less than $1 \%$ of an absorbed dose of isoflurane undergoes biotransformation in the body ${ }^{3}$ the potential for fluoride-induced nephrotoxicity is low. However, the prolonged use of isoflurane in children $^{4}$ and adults ${ }^{3}$ with sometimes unpredictable increases in serum levels of inorganic fluoride has led to concerns about the potential for inorganic fluoride nephrotoxicity. ${ }^{5}$

We would like to report on the prolonged use of isoflurane for management of status asthmaticus in two patients. The first was a 19-yr-old woman known asthmatic who presented to a referring hospital in status asthmaticus. At the referring centre she was ventilated using isoflurane intermittently over $48 \mathrm{hrs}$ before transfer to our institution. The total MAC hours of Isoflurane administration before transfer is unknown. However, at our institution, she was administered isoflurane for three days ranging from $0.4-1.0 \%$. This resulted in $55 \mathrm{MAC}$ hr isoflurane. However, the total amount of isoflurane received was certainly higher but unfortunately unavailable. The second patient was a 41-yr-old woman with a history of asthma. Within several hours of her presentation, treatment with isoflurane by inhalation was begun for severe bronchospasm. This patient received seven days of iso- 